\title{
The influence of radio frequency ablation on intra-articular fluid temperature in the ankle joint - a cadaver study
}

\author{
Philipp Ahrens ${ }^{1,2 \dagger}$, Dirk Mueller ${ }^{3+}$, Sebastian Siebenlist ${ }^{1 *}$, Andreas Lenich ${ }^{1,4}$, Ulrich Stoeckle ${ }^{5}$ \\ and Gunther H. Sandmann ${ }^{5,6}$
}

\begin{abstract}
Background: Radio frequency ablation devices have found a widespread application in arthroscopic surgery. However, recent publications report about elevated temperatures, which may cause damage to the capsular tissue and especially to chondrocytes. The purpose of this study was the investigation of the maximum temperatures that occur in the ankle joint with the use of a commercially available radio frequency ablation device.

Methods: Six formalin-fixed cadaver ankle specimens were used for this study. The radio frequency device was applied for $120 \mathrm{~s}$ to remove tissue. Intra-articular temperatures were logged every second for $120 \mathrm{~s}$ at a distance of 3,5 and $10 \mathrm{~mm}$ from the tip of the radio frequency device. The irrigation fluid flow was controlled by setting the inflow pressure to $10 \mathrm{mmHg}, 25 \mathrm{mmHg}, 50 \mathrm{mmHg}$ and $100 \mathrm{mmHg}$, respectively. The controller unit voltage setting was set to 1,5 and 9 .

Results: Maximum temperatures exceeding $50^{\circ} \mathrm{C} / 122^{\circ} \mathrm{F}$ were observed for all combinations of parameters, except for those with a pressure of $100 \mathrm{mmHg}$ pressure. The main critical variable is the pressure setting, which is highly significant. The controller unit voltage setting showed no effect on the temperature measurements. The highest temperature was $102.7^{\circ} \mathrm{C} / 215.6^{\circ} \mathrm{F}$ measured for an irrigation flow of $10 \mathrm{mmHg}$. The shortest time span to exceed $50^{\circ} \mathrm{C} / 122^{\circ} \mathrm{F}$ was $3 \mathrm{~s}$.

Conclusion: In order to avoid temperatures exceeding $50^{\circ} \mathrm{C} / 122^{\circ} \mathrm{F}$ in the use of radio frequency devices in arthroscopic surgeries of the ankle joint, it is recommended to use a high irrigation flow by setting the pressure difference across the ankle joint as high as feasible. Even short intervals of a low irrigation flow may lead to critical temperatures above $50^{\circ} \mathrm{C} / 122^{\circ} \mathrm{F}$.
\end{abstract}

Level of Evidence: Level II, diagnostic study.

Keywords: Ankle joint, Radio frequency, Ablation, Thermal damage, Chondrocytes

\section{Background}

Arthroscopic surgery of the ankle joint is widespread and tissue ablation is one of the main indications in the "Soccer's Ankle" or anterior impingement. In this condition, fibrous tissue causes pain above the anterior aspect of the ankle joint and the removal of this tissue is an

\footnotetext{
* Correspondence: Sebastian.siebenlist@mri.tum.de

†Philipp Ahrens and Dirk Mueller contributed equally to this work.

${ }^{1}$ Department of Orthopaedic Sports Medicine, Klinikum rechts der Isar,

Technische Universitaet Muenchen, Germany, Ismanninger, Str. 22, D- 81675

Muenchen, Germany

Full list of author information is available at the end of the article
}

adequate therapy to provide pain-free motion. Most of these devices use electromagnetic energy for shrinking, coagulation or ablation of tissue [3, 4]. In contrast, we used a bipolar device in which the energy comes from a plasma layer at the tip of the wand. Radio frequency (RF) ablation devices are widely used to remove soft tissue in arthroscopic surgery. The basic idea of a RF device is to destroy soft tissue by electrolyte plasmarization with the side effect of increased heating of the irrigation fluid. To avoid intraarticular heat, the RF device has vents that are inset at the tip to increase the outflow of the arthroscopic irrigation fluid. Unfortunately, some

(c) The Author(s). 2018 Open Access This article is distributed under the terms of the Creative Commons Attribution 4.0 International License (http://creativecommons.org/licenses/by/4.0/), which permits unrestricted use, distribution, and reproduction in any medium, provided you give appropriate credit to the original author(s) and the source, provide a link to the Creative Commons license, and indicate if changes were made. The Creative Commons Public Domain Dedication waiver (http://creativecommons.org/publicdomain/zero/1.0/) applies to the data made available in this article, unless otherwise stated. 
hot water, gas and denatured material may escape into the joint cavity where it might lead to unwanted increased local temperatures. Recent publications have shown dermal burns of patients due to hot water spilling originating from the RF ablation process and there are also some cases of glenohumeral chondrolysis after labral repair in hip arthroscopy [1-7]. Different reports investigated safety limits and found that chondrocyte damage may occur at temperatures as low as $45^{\circ} \mathrm{C} / 113^{\circ}$ F. Evaluations of the ability of the chondrocytes to recover showed a sharp increase of chondrocyte death between 50 to $55^{\circ} \mathrm{C}\left(122\right.$ to $\left.131{ }^{\circ} \mathrm{F}\right)[8,9]$. Thus, in recent publications on temperatures in shoulder joints [10] and hip joints [11], a $50^{\circ} \mathrm{C} / 122^{\circ} \mathrm{F}$ criterion was used as limit for safe temperatures. Both publications report temperatures exceeding the critical point of $50^{\circ} \mathrm{C}$, which can easily be reached by RF ablation in the shoulder and hip joints depending on the flow of the irrigation fluid and their extraction. Until now, only limited data exists on the effects of RF ablation in the ankle joint, where especially the resection of hypertrophic synovia is useful and frequently used [12].

Anatomically, the capsular volume of the hip (2.5-10 ml) [13] is comparable to the volume of the ankle joint $(6-10 \mathrm{ml})$ [14]. We therefore hypothesized that temperatures exceeding $50^{\circ} \mathrm{C} /\left(122^{\circ} \mathrm{F}\right)$ may be reached by $\mathrm{RF}$ ablation. In our study, we wanted to investigate the impact of the irrigation flow rate, the controller unit voltage setting and the distance from the heat source on maximum temperatures, mean temperatures, time to reach the $50^{\circ}$ $\mathrm{C} / 122^{\circ} \mathrm{F}$ limit and - in view of the fact that the results of thermo-fluid dynamics experiments may vary substantially - the percentage of experimental runs exceeding $50^{\circ} \mathrm{C} / 122^{\circ} \mathrm{F}$ with the same parameter settings.

\section{Methods}

A controlled laboratory study was designed using six formalin-fixed human cadaver ankle joints. All human specimen enrolled in this study were post-mortem donors to the Anatomical Institute of the University of Munich. The use of donated post-mortem specimens for scientific investigations is in accordance with the Declaration of Helsinki and was approved by the ethical committee of the University of Munich. Surrounding soft tissue around the ankle was preserved. The experiments were performed at room temperature using an antero-medial and antero-lateral portal. The irrigation inflow was placed in the antero-medial portal, while the bipolar RF device "Ambient Super Turbo Vac 90 IFS" with the Quantum II controller (Arthocare Corporation, Austin, Texas, USA) was placed via the antero-lateral portal (Fig. 1). The device uses a physical bipolar radio frequency process to stimulate electrolytes in the conductive natrium chloride solution. The energized particles in the plasma denaturize organic molecular bonds and dissolve tissue at temperatures between $40^{\circ} \mathrm{C}$ and $70^{\circ} \mathrm{C} / 104^{\circ} \mathrm{F}$ and $158^{\circ} \mathrm{F}$, a current does not pass through the tissue. The result is volumetric removal of the target tissue with marginal collateral tissue damage. The RF device has vents at the tip, which are the outlets for the arthroscopic fluid. The Quantum II controller measures the temperature at the vents and cuts the power supply when temperatures exceed $40^{\circ} \mathrm{C} / 104^{\circ} \mathrm{F}$. Different voltage levels are possible, allowing a potential adaption according to the tissue treated.

All measurements were performed under direct arthroscopic vision, providing a free and unobstructed flow path for the irrigation fluid. To measure the temperature inside the ankle joint, three thermoprobes (TP) were placed 3, 5 and $10 \mathrm{~mm}$ off the tip (Fig. 2). Continuous temperature

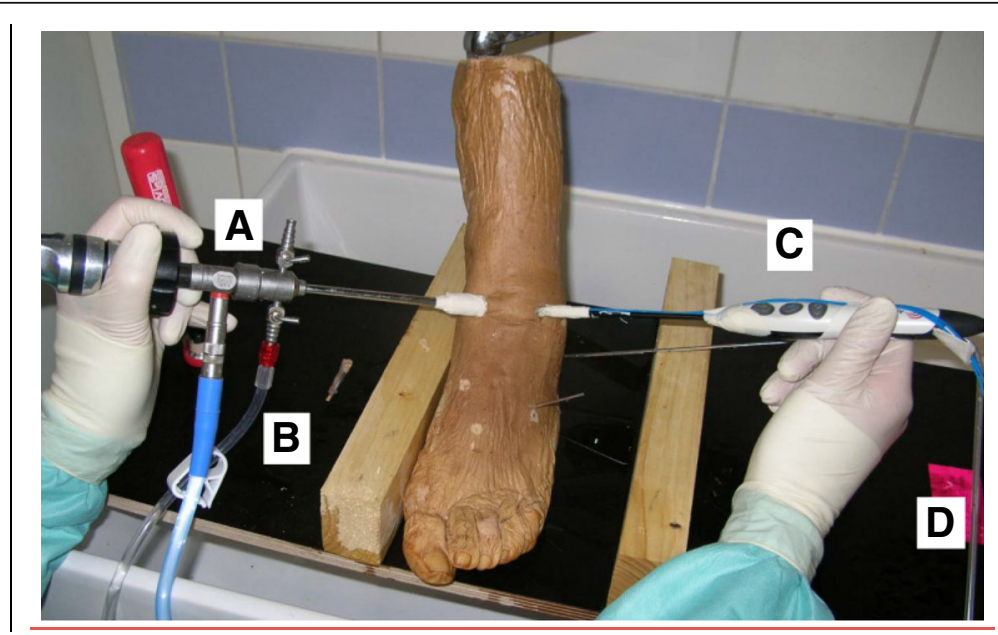

Fig. 1 The laboratory setup used in this study with the arthroscope (A) and the irrigation hose (B) on the left side in the antero-medial portal and the bipolar radiofrequency device $(C)$ in the antero-lateral portal. The thermometer probes are attached to the device. The radio frequency device was moved during the ablation process 
measurement was performed by a multichannel fiberoptical thermometer unit, which is sensitive enough to detect temperature changes of $0.01{ }^{\circ} \mathrm{C}$. Temperatures were recorded and analyzed each second, while a measurement cycle took $120 \mathrm{~s}$. In our view, the flow is the key parameter to excess heat in arthroscopy (Fig. 3). In order to vary the plasma power inside the cavity, the voltage was set from 1 to 5 and 9 at the end (minimum, medium and maximum level). The irrigation flow was controlled using the inlet pressures with 10, 25, 50 and $100 \mathrm{mmHg}$. The experiments started at room and irrigation fluid temperature of $20^{\circ} \mathrm{C} / 68^{\circ} \mathrm{F}$. During the $120 \mathrm{~s}$, there is very little conductive heat flow from the cavity to the surrounding tissue and the heat capacity of the fluid in the ankle joint cavity is small $(5-10 \mathrm{ml})(1)$. The experiments show that the heat escaping from the RF device leads to a heat build-up within $20 \mathrm{~s}$ at low coolant flow conditions. This clearly indicates that using $37{ }^{\circ} \mathrm{C} / 98.6^{\circ} \mathrm{F}$ instead of $20^{\circ} \mathrm{C} / 68^{\circ} \mathrm{F}$ does not affect the maximum temperatures, but only reduces the time span before the stationary conditions are reached by a few seconds.

After having run four experiments for each combination as mentioned above, we analyzed our material and found that all experiments with the $100 \mathrm{mmHg}$ pressure setting did not exceed the $50^{\circ} \mathrm{C} / 122^{\circ} \mathrm{F}$ criterion, while the criterion was exceeded at least in one experiment for the other parameter combinations. However, we found no detectable effect of the voltage settings. Thus, the experiments with the same pressure setting are statistically in the same group, which means that we had 12 experiments for each pressure setting, which is sufficient for a meaningful statistical evaluation.

\section{Statistical analysis}

Statistical analysis was performed using the software package SPSS $^{\text {tu }}$ (Version 19, IBM ${ }^{\otimes}$ Corporation, Somers,
New York, USA) and the software EXCEL from Microsoft Office 2010 Professional. The temperature time histories were assessed and evaluated with EXCEL. Also, bounding curves and maxima and mean values were calculated with EXCEL. Linear regression analysis of the maximum and mean values was performed with both programs, SPSS and EXCEL. For the evaluation of the data, a $p$-value of 0.05 was assumed.

\section{Results}

Low, medium and high pressure temperature curves

In order to eliminate random effects, bounding curves were calculated for maximum temperatures for each pair of parameter settings for voltage and pressure position by averaging the TP positions and the four experimental runs. It was found that the maximum curves can be divided into three groups: low pressure $(10 \mathrm{mmHg})$, medium pressure $(25$ and $50 \mathrm{mmHg}$ ) and high pressure (100 mmHg).

Figure 4 shows the resulting maximum curves for the low pressure setting. Without doubt, it is obvious that low pressure is not an option for ankle joint RF ablation - independent of the voltage setting.

Figure 5 shows the resulting maximum curves for the medium pressure setting ( 25 and $500 \mathrm{mmHg}$ ). All curves show strong fluctuations and an overall upward tendency. All curves exceeded the $50^{\circ} \mathrm{C} / 122^{\circ} \mathrm{F}$ criterion, for curves with $50 \mathrm{mmHg}$ pressure, it takes some seconds longer. It is worse that the $50^{\circ} \mathrm{C} / 122^{\circ} \mathrm{F}$ criterion is exceeded in all curves, if the time span is longer than 50 $\mathrm{s}$ in all cases. This means that an improved and more realistic version of the $50^{\circ} \mathrm{C} / 122^{\circ} \mathrm{F}$ criterion is not feasible, e.g. a criterion like "surpassing the $50{ }^{\circ} \mathrm{C} / 122{ }^{\circ} \mathrm{F}$ for a time span for less than 10 seconds", in which no damage can be done because the time span is too short for a substantial heat build-up of the tissue.

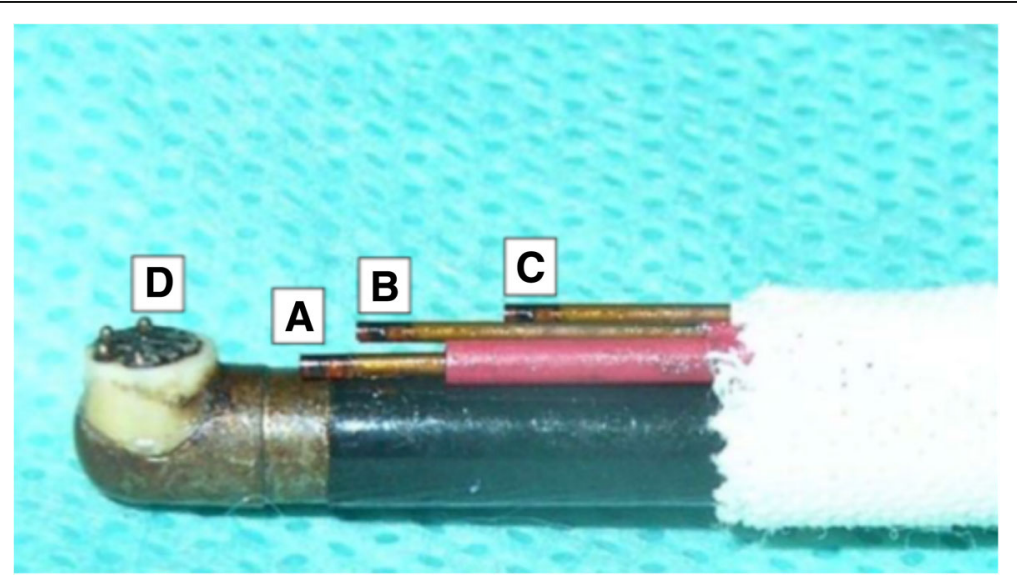

Fig. 2 Three fiberoptical thermometer probes were attached to the radio frequency ablation device at $3 \mathrm{~mm}$ (A), $5 \mathrm{~mm}$ (B) and $10 \mathrm{~mm}$ (C) from the electrode plate with four ball electrodes where the heat is generated. The suction inlet consists of six triangular holes in this plate (D) 


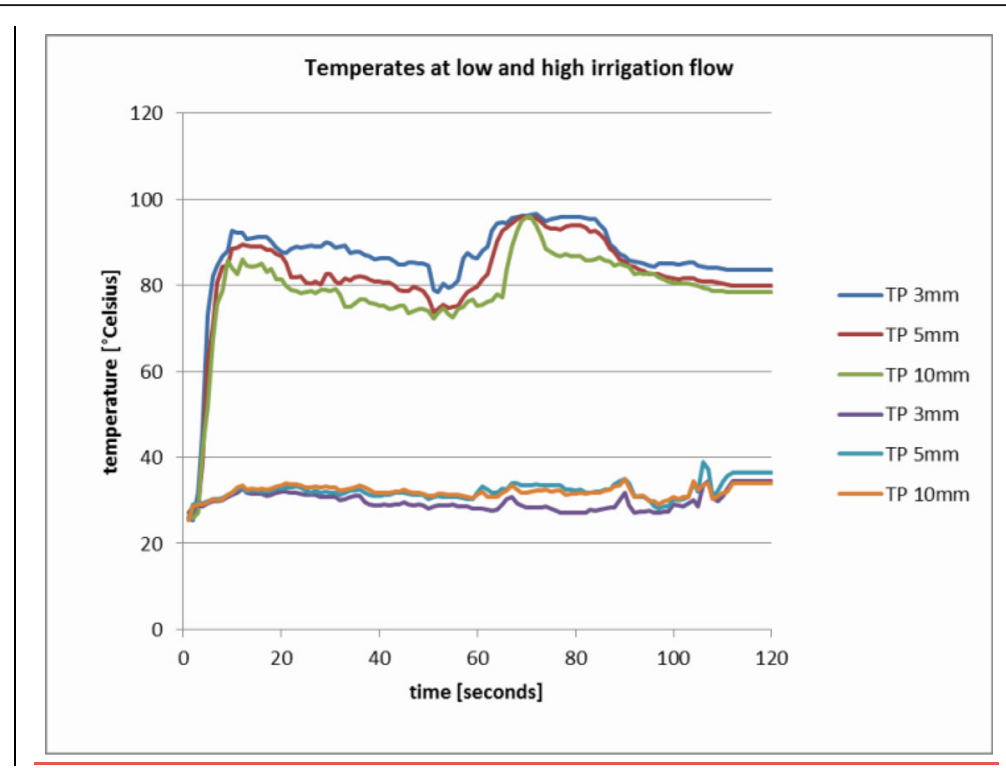

Fig. 3 This figure shows temperature plots for an experiment with a pressure setting of $10 \mathrm{mmHg}$ (three curves on the top) and with $100 \mathrm{mmHg}$ (three bottom curves) for three thermometer probes at 3,5 and $10 \mathrm{~mm}$ distance. For $10 \mathrm{mmHg}$, a rapid heat build-up is observed within the first $10 \mathrm{~s}$. After the heat build-up, the temperature curves fluctuate around the average temperature. For $10 \mathrm{mmHg}$, the temperature fluctuations are more rapid and have smaller amplitudes than for $100 \mathrm{mmHg}$

Figure 6 shows the resulting maximum curves for the high pressure setting $(100 \mathrm{mmHg})$. These stay clearly below the $50{ }^{\circ} \mathrm{C} / 122^{\circ} \mathrm{F}$ criterion, show a stationary mean and only small fluctuation amplitudes. This indicates that using RF ablation with $100 \mathrm{mmHg}$ is safe.

Figure 7 shows the mean temperatures for all voltage settings (1, 5 and 9) and all pressures (10, 25, 50 and $100 \mathrm{mmHg}$ ). The mean temperatures for the low pressure setting are substantially higher than the medium and high pressures. The range of mean temperatures at high pressure is marked by dotted lines forming a rectangle. Some of the temperatures at medium pressures stay within the dotted lines for some time and then rise above the upper boundary, while others are clearly above this range most of the time. The overall behavior of the mean temperatures is similar to the overall behavior of the maximum temperatures as far as the influence of the different pressure settings is concerned.



Fig. 4 All maximum temperature curves for the different voltage settings 1,5 and 9 and at low pressure of $10 \mathrm{mmHg}$ are similar. Within a few seconds, the $50^{\circ} \mathrm{C}$ criterion is exceeded and the temperature remains at high values of about $90^{\circ} \mathrm{C}$ for the rest of the time 


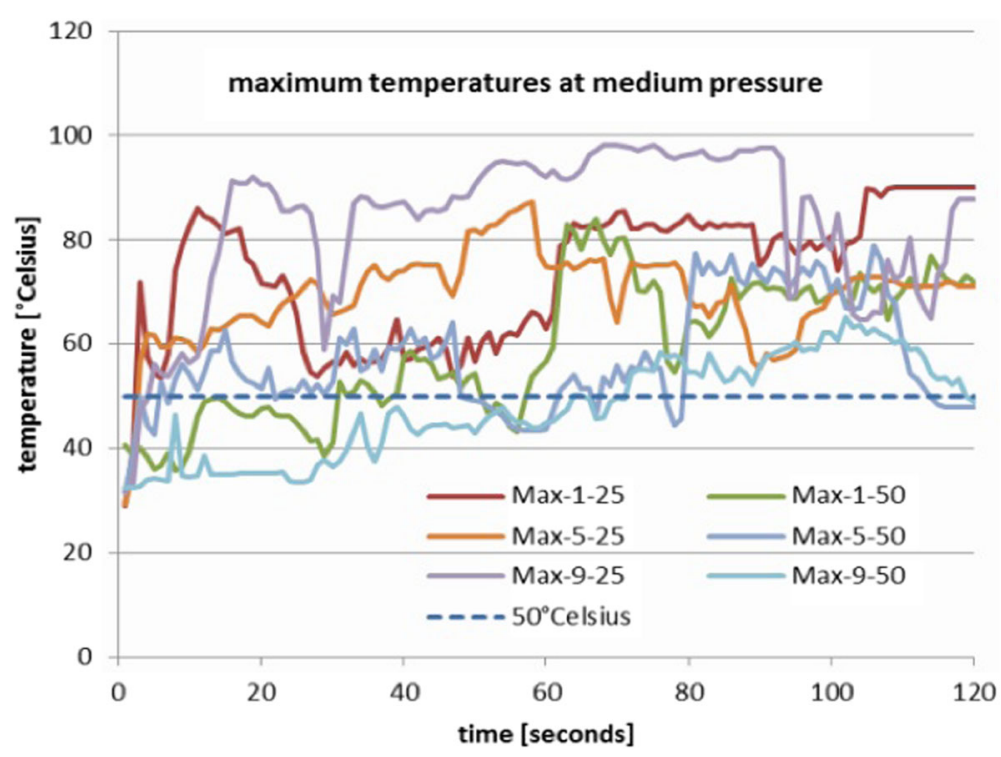

Fig. 5 Maximum temperatures for voltage settings 1, 5 and 9 at medium pressure ( 25 and $50 \mathrm{mmHg}$ ). The curves show a strong oscillatory behavior and an upward tendency. All curves exceed the $50^{\circ} \mathrm{C}$ criterion, lasting some seconds longer for curves with $50 \mathrm{mmHg}$

\section{Regression analysis}

In order to substantiate the expectations from a "quick look" analysis of the data and the physical interpretation of the process, regression analysis of the overall maximum and mean temperatures was carried out starting with the three parameters: voltage setting, square root of pressure and TP distance. Then, the parameter, which had the least effect was eliminated in two additional steps: in the second step, the voltage setting was eliminated and in the third step the TP distance. In a linear regression analysis, a multi-linear response surface is constructed that minimizes the distance of the measured data from the surface. The parameter R-squared is the proportion of variance of the maximum or mean temperature, respectively, which can be explained by the independent variables pressure, TP distance and voltage setting. We found that about $80 \%$ of the variances can be explained by the two variables pressure and TP distance. The $p$-value for the pressure is highly significant $(p<0.001)$, while the $\mathrm{p}$-value for the TP distance is 0.011 for the mean temperature and 0.039 for the maximum temperature. This finding is in good compliance

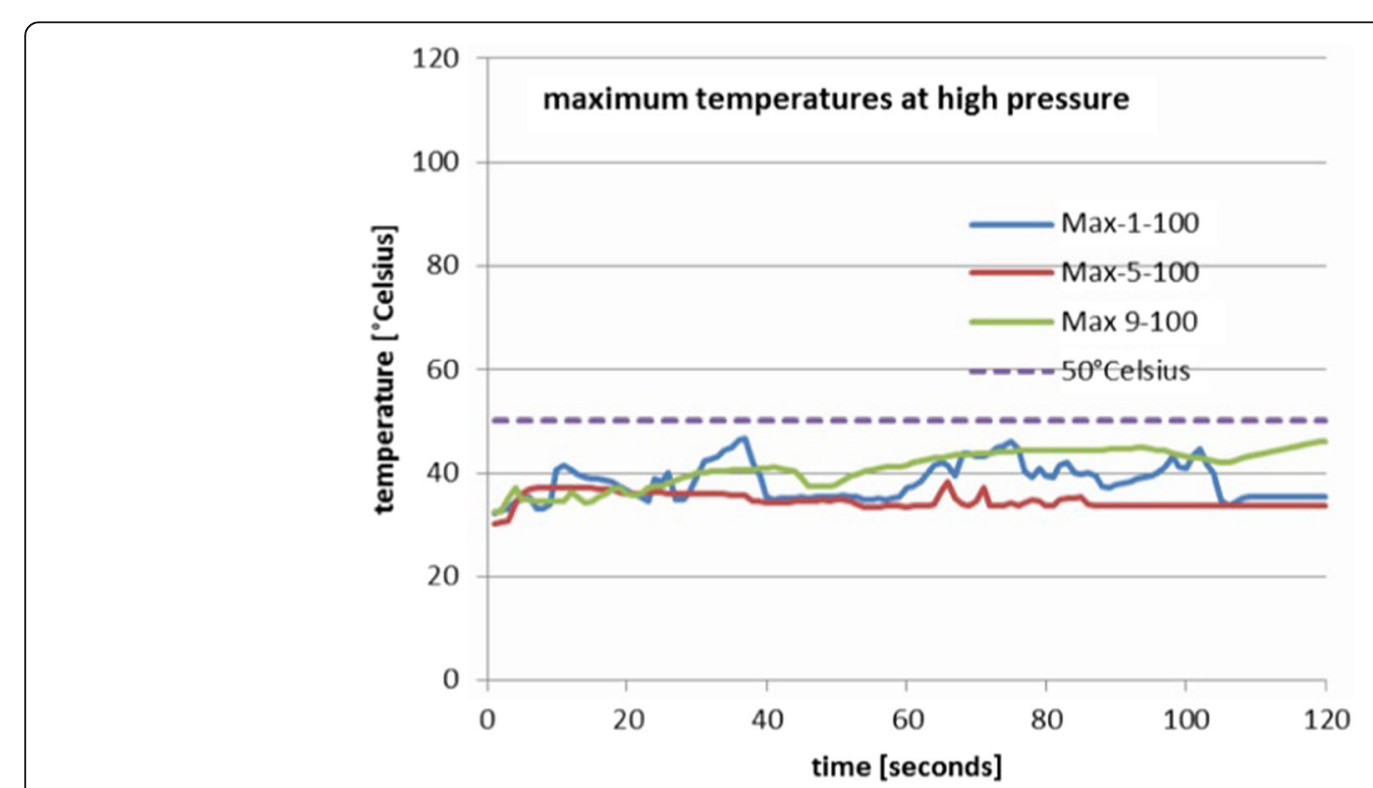

Fig. 6 Maximum temperature for voltage settings 1, 5 and 9 at high pressure $(100 \mathrm{mmHg})$. All curves remain below the $50^{\circ} \mathrm{C}$ criterion 


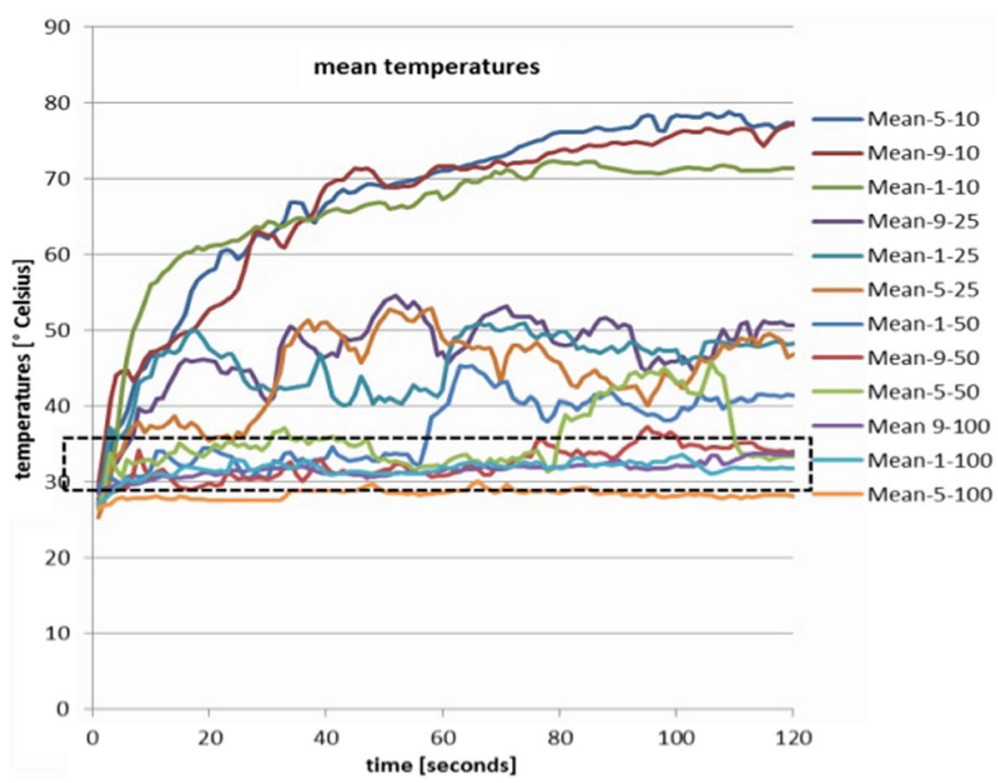

Fig. 7 Mean temperatures for all voltage settings (1,5 and 9) and all tested pressures (10, 25, 50 and $100 \mathrm{mmHg}$ ). The mean temperatures for the low pressure are substantially higher than the medium and high pressures. The range of mean temperatures at high pressure is marked by the dotted rectangle. Some of the temperatures at medium pressures stay within this rectangle for a limited amount of time, while others are clearly above this range all the time

with the temperature fluctuations due to thermal convection, which may lead to a situation where the most distant TP sees higher temperatures than the TPs closer to the RF device with a certain probability. The $\mathrm{p}$-value for the voltage setting is 0.856 for the mean and 0.818 for the maximum temperature, which means that any connection of the mean and maximum temperatures with the voltage setting is random. In summary, voltage setting did not have any impact on the maximum and mean temperatures and the key parameter to control the temperatures is pressure.

\section{Specific findings on individual experimental runs}

Until now, we have presented findings on maximum and mean temperatures calculated by averaging the experimental runs. Next, the specifics of the individual runs will be addressed. It is characteristic for experiments in thermo-fluid dynamics in which some turbulence is generated that the temperature-time functions vary substantially from one experimental run to the next due to the dynamics of flow patterns and fluctuations. Running the same experiment with the parameters kept constant may result in temperature curves that differ substantially and fundamental aspects can only be identified by averaging various runs. A closer view on the individual violations of the $50{ }^{\circ} \mathrm{C}$ criterion illustrates this issue. In $100 \%$ of the low pressure experiments, the criterion was violated. In the medium pressure range for the $25 \mathrm{mmHg}$ experiments, it was found that $66 \%$ of the experimental runs violated the criterion, while for the $50 \mathrm{mmHg}$ runs only
$38 \%$ violated the criterion. In the high pressure experiment, no violation was observed. Table 1 shows more details on the individual findings [11].

The main findings presented in this table are

1) The shortest time span in which $50^{\circ} \mathrm{C} / 122^{\circ} \mathrm{F}$ were reached was $2 \mathrm{~s}$.

2) The highest maximum temperature was $102.7^{\circ} \mathrm{C}$ (exceeding the boiling point of the saline fluid used as irrigation fluid) in experiments with low pressure and $32.4^{\circ} \mathrm{C} / 89.6^{\circ} \mathrm{F}$ in experiments with high pressure.

3) The percentage of runs that exceed the criterion is an almost exact linear function of the square root of pressure.

4) The mean temperature ranges from $77.0^{\circ} \mathrm{C} / 170.6^{\circ} \mathrm{F}$ at low pressure to $27.1^{\circ} \mathrm{C} / 80.6^{\circ} \mathrm{F}$ at high pressure.

\section{Discussion}

The purpose of this study was to investigate the effect of RF use in the ankle joint and how the three parameters irrigation fluid pressure, thermometer probe distance from the wand tip and the voltage setting of the controller affect the maximum temperatures in the ankle joint. The purpose was also to derive recommendations for the safe use of RF in the ankle joint. 
Table 1 Incidence of damaging temperatures reached Column 1 to 3 give the independent parameters. Column 4 lists the time needed to achieve temperatures above $50^{\circ} \mathrm{C}$. Column 5 lists the maximum temperatures observed in an individual experimental run

\begin{tabular}{|c|c|c|c|c|c|c|}
\hline \multicolumn{3}{|l|}{ Parameters } & \multicolumn{2}{|l|}{ Individual } & \multicolumn{2}{|l|}{ Mean } \\
\hline controller voltage setting & $\begin{array}{l}\text { flow pressure } \\
{[\mathrm{mm} \mathrm{Hg}]}\end{array}$ & $\begin{array}{l}\text { Thermometer probe } \\
\text { distance }[\mathrm{mm}]\end{array}$ & $\begin{array}{l}\text { first time } \\
\geq 50^{\circ} \mathrm{C}[5]\end{array}$ & $\mathrm{T}_{\max }\left[{ }^{\circ} \mathrm{C}\right]$ & $\begin{array}{l}\text { Percentage of } \\
\text { runs with } \\
T_{\text {max }} \geq 50^{\circ} \mathrm{C}\end{array}$ & $\begin{array}{l}\text { Average Temp } \\
{\left[{ }^{\circ} \mathrm{C}\right] \text { of all runs }}\end{array}$ \\
\hline \multirow[t]{3}{*}{1} & 10 & 3 & 4 & 96,5 & $100 \%$ & 72,3 \\
\hline & & 5 & 5 & 96,0 & $75 \%$ & 66,4 \\
\hline & & 10 & 5 & 95,8 & $75 \%$ & 58,4 \\
\hline \multirow[t]{3}{*}{1} & 25 & 3 & 3 & 90,0 & $75 \%$ & 52,7 \\
\hline & & 5 & 3 & 88,5 & $75 \%$ & 47,6 \\
\hline & & 10 & 7 & 74,7 & $25 \%$ & 36,6 \\
\hline \multirow[t]{3}{*}{1} & 50 & 3 & 31 & 47,6 & $40 \%$ & 38,2 \\
\hline & & 5 & 58 & 48,2 & $40 \%$ & 37,0 \\
\hline & & 10 & 58 & 46,4 & $20 \%$ & 35,6 \\
\hline \multirow[t]{3}{*}{1} & 100 & 3 & $X X$ & 46,6 & $0 \%$ & 33,4 \\
\hline & & 5 & $X X$ & 37,8 & $0 \%$ & 31,9 \\
\hline & & 10 & $X X$ & 38,5 & $0 \%$ & 30,0 \\
\hline \multirow[t]{3}{*}{5} & 10 & 3 & 4 & 102,7 & $100 \%$ & 77,0 \\
\hline & & 5 & 8 & 98,6 & $100 \%$ & 65,7 \\
\hline & & 10 & 8 & 96,5 & $100 \%$ & 60,3 \\
\hline \multirow[t]{3}{*}{5} & 25 & 3 & 3 & 87,2 & $0 \%$ & 53,1 \\
\hline & & 5 & 30 & 87,4 & $25 \%$ & 42,7 \\
\hline & & 10 & 37 & 74,2 & $50 \%$ & 37,3 \\
\hline \multirow[t]{3}{*}{5} & 50 & 3 & 3 & 78,9 & $50 \%$ & 39,6 \\
\hline & & 5 & 23 & 69,6 & $50 \%$ & 36,9 \\
\hline & & 10 & 91 & 57,9 & $50 \%$ & 30,8 \\
\hline \multirow[t]{3}{*}{5} & 100 & 3 & $X X$ & 37,2 & $0 \%$ & 29,6 \\
\hline & & 5 & $X X$ & 38,3 & $0 \%$ & 28,4 \\
\hline & & 10 & $X X$ & 37,2 & $0 \%$ & 27,1 \\
\hline \multirow[t]{3}{*}{9} & 10 & 3 & 2 & 99,6 & $100 \%$ & 72,4 \\
\hline & & 5 & 3 & 100,5 & $75 \%$ & 67,5 \\
\hline & & 10 & 20 & 92,3 & $75 \%$ & 60,2 \\
\hline \multirow[t]{3}{*}{9} & 25 & 3 & 5 & 98,2 & $75 \%$ & 55,6 \\
\hline & & 5 & 13 & 95,2 & $75 \%$ & 49,8 \\
\hline & & 10 & 104 & 80,5 & $50 \%$ & 36,2 \\
\hline \multirow[t]{3}{*}{9} & 50 & 3 & 72 & 58,6 & $25 \%$ & 32,9 \\
\hline & & 5 & 64 & 46,2 & $25 \%$ & 33,8 \\
\hline & & 10 & $X X$ & 35,9 & $0 \%$ & 30,5 \\
\hline \multirow[t]{3}{*}{9} & 100 & 3 & $X X$ & 46,1 & $0 \%$ & 33,1 \\
\hline & & 5 & $X X$ & 40,4 & $0 \%$ & 32,1 \\
\hline & & 10 & $X X$ & 32,4 & $0 \%$ & 29,9 \\
\hline
\end{tabular}

There have been several reports about the deleterious effects of thermal damage to chondrocytes in shoulder arthroscopy resulting in chondrolysis $[15,16]$ and other papers indicate that a $50^{\circ} \mathrm{C} / 122^{\circ} \mathrm{F}$ criterion should be observed since only temperatures below $50{ }^{\circ} \mathrm{C} / 122^{\circ} \mathrm{F}$ seem to be safe [9]. Two papers on the effect of RF use in the hip joint [11] and the shoulder joint [10] were published recently. Both papers found that temperatures in the joint, which exceed the criterion of $50^{\circ} \mathrm{C} / 122^{\circ} \mathrm{F}$, can be measured under no flow or low flow of irrigation 
fluid. From the analysis of the physical problem, it follows that the power output of the RF wand and the amount of irrigation flow are the key parameters, which influences the thermo-fluid dynamics. A typical phenomenon in thermo-fluid dynamics is temperature fluctuation. To measure these fluctuations close to the tip of the wand, three TPs were attached to the wand. From the physical analysis, it is also clear that there are many other parameters which may influence the temperature and which are not controlled in the experiment and therefore provide a random contribution to the data.

As the ankle joint volume $(6-10 \mathrm{ml})$ is similar to the volume of the hip joint cavity $(2.5-10 \mathrm{ml})$, we expected findings similar to those in the paper [10]. The regression analysis of the maximum temperatures (absolute maximum) and the mean temperatures (averaged over time) showed that $80 \%$ of the variances can be explained by the square root of the pressure $(p<0.001)$ and by the TP distance, which is also statistically significant $(p<0.05)$.

The effect of the voltage setting of the controller was random, which is hard to understand if one assumes that the voltage setting is relevant for the power output of the RF device. The maximum temperatures of the 12 runs at $100 \mathrm{mmHg}$ were well below the $50^{\circ} \mathrm{C}$ criterion, but for all other pressure settings, some or all runs clearly exceeded the criterion. It has to be concluded that high pressure has to be applied for safe temperatures. The physical analysis indicates that only the pressure difference across the cavity is relevant, thus an additional vacuum at the wand could be used to obtain the same thermo-fluid dynamics in the cavity with lower inlet pressure. The disadvantage of high pressures in the cavity is that water causes edema in the surrounding tissue. The situation can be improved by applying additional suction vacuum to reach the required pressure difference.

One option to reduce maximum temperatures in the ankle joint is the use of a turbulence-generating inflow opening at the arthroscope, which improves thermal mixing.

In addition, two issues were analyzed that might lead to even higher temperatures compared to those observed in this study: Hot non-condensable bubbles and outflow plugging. As the heat capacity of a non-condensable gas is lower than the heat capacity of water or tissue by orders of magnitude, it has to be concluded that hot non-condensable bubbles do not represent a potential hazard. As the RF device emits energized particles that break the molecular bounds within the tissue causing the tissue to dissolve, the ablation process generates more or less vapor and not particles, which might lead to plugging. Nevertheless, plugging cannot be ruled out as tissue may be cut loose and may be sucked into the RF device opening in the ablation process. Comparing the data found in our study and the studies on hip [10] and shoulder ablation [9], we could find similar temperature levels and no significant effect of the joint volume in view of the fact that the glenohumeral joint volume is more than twice the volume of the hip or the ankle joint [13, 14, 17].

Finally, the $50^{\circ} \mathrm{C} / 122^{\circ} \mathrm{F}$ criterion is rather strict and does not reflect the chondrocyte damage mechanism. Obviously, a short contact with $50^{\circ} \mathrm{C}$ will do no harm. Therefore, a better criterion that is based on more sophisticated and in-depth studies should be developed.

We deem the experimental settings of the study to be comparable to the surgical setting. We simulated the use of a RF device and were able to measure temperatures at the tip of the device directly. Although continuous use of the RF device for $60 \mathrm{~s}$ might be extreme, even a shorter time period ( $2 \mathrm{~s})$ is able to cause cartilage damage. Therefore, it is tremendously important to ensure the correct irrigation and thereby diminish the risk of cartilage damage significantly.

In this context, it is crucial to keep in mind that not only high temperatures can have deleterious effects on the surrounding tissue, but also the use of increased water pressure. There have been reports about compartment syndromes of the lower leg after knee arthroscopy with injury to the posterior capsule [18] and of the anterior compartment after ankle arthroscopy in Maisonneuve fractures [19]. Mc Brayer et al. [20] could find an increase of swelling and deltoid muscle pressure during shoulder arthroscopy of $9 \mathrm{mmHg}$ - particularly in operations lasting more than $90 \mathrm{~min}$. Fortunately, they could not find a negative effect on the outcome in their study group.

Still, one has to think of the negative effects of increased pump pressures and what is more, Ross et al. [21] showed in their study that the operative field fluid pressure and the pressure readout might differ considerably.

There are limitations in this study: first, the use of cadaveric specimens leads to a different distraction of the ankle joint and the ankle joint cavity will differ in volume and shape affecting the flow pattern and fluctuations inside the cavity. Six cadaveric specimens cannot represent the full range of variability of human anatomy. Second, the procedure in this study with continuous ablation for more than $60 \mathrm{~s}$ may not reproduce the typical clinical scenario. Third, the cadaveric specimens were evaluated at room temperature and not at normal body temperature. Normal blood flow might work as a heat sink and dissipate heat. However, temperatures above the criterion of $50^{\circ} \mathrm{C} / 122^{\circ} \mathrm{F}$ might be reached even faster at normal body temperature.

\section{Conclusions}

This study investigated the temperatures in the ankle joint during $\mathrm{RF}$ ablation. It showed that the key parameter to guaranty temperatures below the $50{ }^{\circ} \mathrm{C} / 122^{\circ} \mathrm{F}$ 
criterion is irrigation pressure. At pressures of $100 \mathrm{mmHg}$, temperatures in the ankle joint were found to remain well below this criterion. At lower pressure levels, temperatures clearly exceeding $50{ }^{\circ} \mathrm{C} / 122^{\circ} \mathrm{F}$ were reached in some or all experiments. Until a more sophisticated in-depth study reveals more detailed information on the effect of RF ablation on the temperatures in the ankle joint and potential hazard for chondrocytes, the authors recommend to keep the pressure difference across the ankle joint as high as feasible, the ablation time short and the temperature of the irrigation fluid low.

\section{Abbreviations}

RF: Radiofrequency; TP: Thermoprobe

\section{Availability of data and material}

To request the raw data, the last author of the manuscript can be contacted: Dr. Gunther Sandmann, Sportklinik Ravensburg, Bachstr. 57, 88,214 Ravensburg. Tel.: 0049-751, 366 17,620,E-Mail: g_sandmann@hotmail.com

\section{Funding}

No funding was obtained for this study.

\section{Authors' contributions}

All authors contributed in a significant way in the steps of processing the patient history as well as writing and editing the manuscript. GHS and PA conceived the idea for the study/publication and engaged in writing the first draft. DM, SS and AL provided research support, gave advice throughout the project and were involved in the experiments and the review of the manuscript. AL, US and GHS gave research advice and reviewed the manuscript. All authors read and approved the final manuscript.

\section{Competing interest}

PA is a member of the Editorial Board of BMC Muskuloskeletal Disorders. The other authors have no competing interests.

\section{Ethics approval and consent to participate}

All human specimens enrolled in this study were post mortem donors to the Anatomical Institute of the University of Munich and gave their consent to research and scientific investigations. The use of donated post mortem specimens for scientific investigations is in accordance with the Declaration of Helsinki and was approved by the ethical committee of the University of Munich.

\section{Consent for publication}

Not applicable.

\section{Publisher's Note}

Springer Nature remains neutral with regard to jurisdictional claims in published maps and institutional affiliations.

\section{Author details}

${ }^{1}$ Department of Orthopaedic Sports Medicine, Klinikum rechts der Isar, Technische Universitaet Muenchen, Germany, Ismanninger, Str. 22, D- 81675 Muenchen, Germany. ${ }^{2}$ Sportklinik Stuttgart, Taubenheimstraße 8, D-70372 Stuttgart, Germany. ${ }^{3}$ Schön Klinik Harthausen, Dr.-Wilhelm-Knarr- Weg 1-3, D-83043 Bad Aibling, Germany. ${ }^{4}$ Helios Klinikum München West, Steinerweg 5, D- 81241 Muenchen, Germany. ${ }^{5}$ BG Unfallklinik Tuebingen, Schnarrenbergstraße 95, 72076 Tuebingen, Germany. 'Sportklinik Ravensburg, Bachstraße 57, 88214 Ravensburg, Germany.

Received: 4 February 2018 Accepted: 16 November 2018

Published online: 24 November 2018

\section{References}

1. Kouk SN, Zoric B, Stetson WB. Complication of the use of a radiofrequency device in arthroscopic shoulder surgery: second-degree burn of the shoulder girdle. Arthroscopy. 2011;27:136-41.
2. Troxell CR, Morgan CD, Rajan S, Leitman EH, Bartolozzi AR. Dermal burns associated with bipolar radiofrequency ablation in the subacromial space. Arthroscopy. 2011;27:142-4.

3. Petty DH, Jazrawi LM, Estrada LS, Andrews JR. Glenohumeral chondrolysis after shoulder arthrosocpy: case reports and review of the literature. Am J Sports Med. 2004:32:509-15.

4. Jerosch J, Aldawoudy AM. Chondrolysis of the glenohumeral joint following arthroscopic capsular release for adhesive capsulitis: a case report. Knee Surg Sports Traumatol Arthrosc. 2007;15:292-4.

5. Good CR, Shindle MK, Kelly BT, Wanich T, Warren RF. Glenohumeral chondrolysis after shoulder arthroscopy with thermal capsulorrhaphy. Arthroscopy 2007;23:797 e791-795.

6. Rapley JH, Beavis RC, Barber FA. Glenohumeral chondrolysis after shoulder arthroscopy associated with continuous bupivacaine infusion. Arthroscopy. 2009:25:1367-73.

7. Rehan UI H, Yang HK, Park KS, Lee KB, Yoon TR. An unusual case of chondrolysis of the hip following excision of a torn acetabular labrum. Arch Orthop Trauma Surg. 2010;130:65-70.

8. Horstman $\mathrm{CL}$, McLaughlin RM. The use of radiofrequency energy during arthroscopic surgery and its effects on intraarticular tissues. Vet Comp Orthop Traumatol. 2006;19:65-71.

9. Voss JR, Lu Y, Edwards RB, Bogdanske JJ, Markel MD. Effects of thermal energy on chondrocyte viability. Am J Vet Res. 2006;67:1708-12.

10. Zoric BB, Horn N, Braun S, Millett PJ. Factors influencing intra-articular fluid temperature profiles with radiofrequency ablation. J Bone Joint Sur Am Volume. 2009:91:2448-54.

11. McCormick F, Alpaugh K, Nwachukwu BU, Xu S, Martin SD. Effect of radiofrequency use on hip arthroscopy irrigation fluid temperature. Arthroscopy. 2013;29(2):336-42

12. Arnold H. Posttraumatic impingement syndrome of the ankle--indication and results of arthroscopic therapy. Foot and ankle surgery. 2011;17:85-8.

13. Luke TA, Rovner AD, Karas SG, Hawkins RJ, Plancher KD. Volumetric change in the shoulder capsule after open inferior capsular shift versus arthroscopic thermal capsular shrinkage: a cadaveric model. J Shoulder and Elbow Surg. 2004;13:146-9.

14. Draeger RW, Singh B, Parekh SG. Quantifying normal ankle joint volume: an anatomic study. Indian journal of orthopaedics. 2009:43:72-5.

15. Lu Y, Edwards RB 3rd, Nho S, Heiner JP, Cole BJ, Markel MD. Thermal chondroplasty with bipolar and monopolar radiofrequency energy. effect of treatment time on chondrocyte death and surface contouring Arthroscopy. 2002;18:779-88.

16. Lu Y, Edwards RB 3rd, Nho S, Cole BJ, Markel MD. Lavage solution temperature influences depth of chondrocyte death and surface contouring during thermal chondroplasty with temperature-controlled monopolar radiofrequency energy. Am J Sports Med. 2002;30:667-73.

17. Yen $\mathrm{CH}$, Leung HB, Tse PY. Effects of hip joint position and intra-capsular volume on hip joint intra-capsular pressure: a human cadaveric model. J Orthop Surg Res. 2009:4:8.

18. Keskinbora M, Yalcin S, Oltulu I, Erdil ME, Örmeci T. Compartment syndrome following arthroscopic removal of a bullet in the knee joint after a lowvelocity gunshot injury. Clin Orthop Surg. 2016;8(1):115-8.

19. Imade S, Takao M, Miyamoto W, Hishi H, Uchio Y. Leg anterior compartment syndrome following ankle arthroscopy after Maisonneuve fracture. Arthroscopy. 2009;25(2):215-8.

20. McBrayer DE, Debelak BP, Femicola PJ, Tu R, Baker CL Jr. Deltoid muscle pressures during arthroscopic rotator cuff repair. Orthopedics 2013; 36(1): 33-37.

21. Ross JA, Marland JD, Payne B, Whiting DR, West HS. Do arthroscopic fluid pumps display true surgical site pressure during hip arthrosocpy? Arthroscopy. 2018;34(1):126-32 